\title{
Chapter 9 \\ Talent Management Practices A Trajectory and Ingenuity in Higher Education Institutions: A Meta-analysis Review of Literature
}

\author{
Farooq Miiro and Azam Otham
}

\begin{abstract}
The purpose of the article is to identify talent management practices in higher educational institutions. Meta-analysis literature review was undertaken in order to evaluate the role of talent management in successful attainment of institutional staff quality performance. Through literature review, it was found out that talent management has its share in modern organisational human resource management practices. The study revealed that human resource undoubtedly is an unpredictable resource with multi-coloured responses and attributes towards work; if these attributes are truly discovered, developed and utilised well, then they definitely have an added value on institutional total quality services. The paper also contended that there is a need to investigate its true practice currently embarked on in operations so as to find a suitable theory for the subject and its implication for organisational transformation and excellence.
\end{abstract}

\subsection{Introduction}

With the globalisation trends and the influence of post-modern knowledge economy that have been engulfing and merging the world into one village, human life has become unstable and unpredictable. Every day, the world experiences new dimensions and forces that call for swiftness in human resource management from the known traditional approach to organisational elites. These forces whose clear direction is not well defined surface in human life with unclear

\footnotetext{
F. Miiro $(\bowtie)$

Islamic University in Uganda, Mbale, Uganda

International Islamic University Malaysia, Kuala Lumpur, Malaysia e-mail: miirofarooq@gmail.com
}

\author{
A. Otham \\ International Islamic University Malaysia, Kuala Lumpur, Malaysia
}

(C) Springer International Publishing AG, part of Springer Nature 2018 
ways through which these turbulent moments in the society should be addressed, for example, conflicts, climate changes, health and water management, to mention but a few.

Moreover, when such issues arise, normally the ball is thrown to higher education institutions to find means through which sanity can be restored in the society with respect to human rights. These paradigm shifts cut across both developed and developing countries. Thus, to find a suitable and sustainable culture of the present generations and the future, the education system has begun to realise the need for talented human resources who are agile, privy and astute in nature with an aim of addressing the millennial demands using higher education as a tool for real-life solutions (Sahney et al. 2004). The complex and heterogeneous world that calls for massification and internationalisation of higher education institutions can be attributed to technological hastening and global village that demand for intellectual stature.

Looking at the above given explanations, there is no doubt that the only way to address global work force sustainability growth in higher education institutions is through talent management practices. This is because the way of thinking among institutional leaders to survive in this global era is far different from yesterday in terms of capacity building and the knowledge economy issues. It is equally important to note that the well-trained and skilled staff are the only pivotal point that can be able to produce graduates with vast knowledge. The globalisation goals and education standards require a flexible human intellect that can easily handle dynamism and millennial issues through quick and adjustable decision-making implementation (Fraynas et al. 2006; Barsade and Donald 2007).

However, the issue of finding and grooming talented human resources is still an enormous challenge faced by higher education institutions due to the fact that there are two paradoxical situations experienced (Iqbal et al. 2013). There is worldwide surplus of talented human resources but with a shortage at local institution level. This is still worsened by the scarcity of talented young people and abundance of aged people within the education arena. For instance, many universities have more than enough qualified staff, whereas others are understaffed with fewer specialists to boost the institution's corporate image and governance.

That notwithstanding, nowadays, universities are still lagging behind in terms of attracting young people who are talented and skilled. This is attributed to the nature of their life whereby the young graduates are harder to locate and nurture, fragile, too demanding and easier to dissipate and lose (Hernaus 2008). Other studies so far done posit that global companies and multinational firms virtually have no sufficient talent and potential employees to drive their aspirations and strategies ahead (Ready and Conger 2007; Bjorkman et al. 2012). Thus, it is against this background that the paper aims to analyse previous studies' findings on the same matter to establish the role of talent management practices towards higher education transformation so as to compete in the global economy. 


\subsection{What is Talent Management Practices (TMP) and Its Challenges?}

The tempestuous world and its continuous influences appear to suggest changes in beliefs, attitudes and institutional psychology demonstrating that there is a need for transfiguring them so as to cater for concerns of total quality management within higher education institutions (HEIs). However, this point of view looks not to be achievable without talented staff who can cater for curriculum redesigning and quality services. This is because the nature of past university with its traditional approaches towards staff development and its performance cannot possibly withstand the challenges of the Internet that students face in this century and the future generations to come (Scott 2000). In order to play a leading role in addressing transformation challenges, HEIs must reflect on the current situations in the world as a basis to underpin the promise of every child and the generations to come.

Today's generation demands require masses to be holistic and well-developed in terms of critical thinking, communication, innovation, problem solving, entrepreneurship and teamwork so as to fit in a mobile, diverse and non-boundaries culture and place (Al-Atari and Rosnani 2015; Schuler et al. 2011; Scullion et al. 2010; Stahl et al. 2012). As a result, many higher education institutions have moved from the traditional way of managing university business to new direction of focusing on talent management in order to cater for both institutional and stakeholder's interests (Collings et al. 2009; Garavan et al. 2012; Vaiman et al. 2012).

The issue of talent management can be traced way back to old days of 1865 (Simonton 2011); however as time went on, changes and demands of different styles in organisational management came into existence questing for improved services towards workforce reward management. The terminology has also been affected with the changes of the time to fit the broader meaning of what should entail human resources towards revamping organisational performance and image. Talent management is a new phenomenon in the field of millennial human management and education. The aim is to ensure that educational institutions remain relevant to outcompete their sister institutions in the world market through skilled staff that can uphold succession, career planning and growth of both human resources and the institution (Afiouni 2009; Allen 2004; Cappelli 2008).

The study done in the early 1990s, by McKinsey termed as "war on talent", brought new life and face in the field of managing employee shortages towards competitive advantage, organisation excellence and sustainability (Ingham 2006; Tarique and Schuler 2010), thus resulting into several phrases coined from the traditional human resource management systems so as to retain and cut shortages of employees for future quality sustainability. For instance, terms like talent acquisition, retention and management, attraction and development were all brought on board, hence leading to global talent management outcry so as to enhance organisational transformation of employee concerns in order to fit in the competitive knowledge economy and changes in the world market. 
Talent management is all about planning, recruiting and developing systematic ways through which employee training and career growth can be enhanced and sustained towards achievement of educational institutional goals (Othman and Sumardi 2009). The reason behind these constraining efforts by an institutional leadership is to ensure that the mission and vision of the institution is realised through applicability and flexibility to address global challenges (Annakis 2014). The excellence of higher education institutions can be observed through rebranding and reshaping the economic transformation of a nation through inventory of new academic programmes, research and facilities that attract internationalisation (Isahak 2007).

As stated above, the term talent management practices is still in its early stages with no clear-cut boundaries of what should entail. However, many studies so far done in these few years have tried to come up with several detailed meanings. For example, Collings et al. (2009) refer to it as a strategy of filling key positions of organisational chart with suitable persons of high potential performance calibre to enhance organisational performance excellence in the dynamic competitive environment. This can only be achieved through continued development of employees for sustainability and commitment towards organisational transformation. It is also important to note that key vacancies do not only imply top management positions but they combine all influential parts of the systems that enhance organisational development since both leaders and managers co-work towards achievement of targeted goals.

Since talent management practices involve salient key issues of talent identification, talent development, talent culture and competencies, Davies and Davies' (2010) model on talent management ensures succession planning and functioning systems and structures. There is no way out how higher education institutions can distance themselves from investing in human power for sustainable leadership and quality services management. However, there are still some disturbing issues on what should entail this terminology (Lewis and Heckman 2006). In a survey study conducted in the UK about human resource professionals, the findings revealed that $51 \%$ knew what talent management practices is all about whereas $20 \%$ only were vividly operating in a known definition by CIPD (2006). Hence, many schools of thought are defining it in a manner that suits their research coverage due to lack of theoretical framework to guide these definitions (Boundreau and Ramstad 2005).

Talent management can further be viewed as potential skilful employees for sustainable competitive advantage (Becker and Huselid 2006). It is about succession management planning and strategies so as to maintain organisational excellence. Talent management in detailed meaning is viewed as the process of developing and attracting skilled employees to boost the institutional vision and mission. This is done through identifying the gaps within influential positions purposely for succession planning and recruitment. It is implemented within higher education institutions as a motivating factor in order to retain and attract staff commitment towards organisational transformation (Gutheridge et al. 2008; Ringo et al. 2008).

Nevertheless, other authors define it as identification of good things to invest in good people within an organisation to enhance both staff and institutional develop- 
ment within them capitalising on their strength (Garrow and Hirsh 2008). It is embedded within a combination of sharp minds, leadership skills and ability to attract and inspire young blood towards better service delivery (Chuai et al. 2010). Even though studies and scholars have divergent views on the definition of what talent management practices should entail, they all share certain aspects in common. For instance, the goal of talent management is to attract, recruit, develop and retain employees for creating succession plans so as to achieve organisational goals through staff commitment and use of tactical skills and experience (Goffee and Jones 2007; Ingham 2006; Cheese et al. 2008).

Given the fact that so far there is no propounded theory on which all scholars zero on to define talent management and practices, the researchers summarised their definitions within one statement to fit this study. Talent management practices mean planning and identification of potential personnel for recruitment and development to transform organisational performance through retention and commitment secured from the staff with in higher education institutions. On the other hand, many studies conducted on this topic in both academic and business sectors have found divergent results still on this matter. The review below is for both studies done in business and higher education sector.

\subsection{Findings of Studies Done in Higher Education Institutions}

In a study done on Malaysian universities by Annakis et al. (2014) with a sample size of 166, $80 \%$ response rate, the findings revealed that four factors emerged explaining $68.6 \%$ of the variation, with $\mathrm{KMO}$ value of 0.812 , which exceeded the recommended value of 0.6 . This is by far the threshold required. On this basis, talent management competency levels for academics are significantly higher if there is integration with the known HR systems, for example, identification of value, team measurement and individual performance, etc. In the same study, findings revealed that there was a relationship between talent management practices in terms of talent identification; therefore, talent development and talent culture seemed to play a critical role towards institutional transformation.

In another study done in Africa, it is evidently clear that from an empirical study done in Botswana by Rudhumbu (2014) using 300 samples of both administrative and teaching staff, $62 \%$ of higher education institutions within that country were providing staff development programme opportunities to enhance their skills and knowledge. Another $42 \%$ agreed that their institutions were able to attract good personnel to occupy important positions of influence, and 33\% had won staff commitment whereas $47 \%$ were performing well.

However, disparities were still experienced from some human resource departments where $57 \%$ did not work hand in hand to support in identifying key institutional talent. Moreover, elsewhere in the world, respondents felt that talent 
management practices are important for organisational performance and development. Whereby, there are particular positions that are special and require special talent competencies to boost organisational directions and achievement. Competency mapping can improve recruitment and selection through identification of the key personnel. Talent acquisition through competency mapping can also be practised in educational sector to ensure right talent at right place. This study was done in India on 50 faculties as sample in higher education sector (Nair 2012).

The study conducted in India by Tiwari and Shrivastava (2013) on the managers and subordinates with a $P$ value of 0.087 and 0.056 , it was found out that there was a significant difference in the impact played by each of TM practices towards level of employee's satisfaction and achievement of organisational targets.

Barkhuizen et al. (2014) in his survey conducted with the main objective of finding out the determinants of the relationship between talent management, work engagement and service orientation of support staff in a South African higher education institution suggested that all the talent management practices are poorly applied for support staff. The same study states that there were gaps between the current applications and the perceived importance of between talent review process, retention practices, talent development and management commitment. However, the same study found out that there is a significant positive relationship between some talent management and work engagement dimensions. This was based on the value at a 95\% confidence interval level $(p \leq 0.05)$ that was attained in the findings.

Nevertheless, a critical review done on some studies by Lyria (2013) in Kenya, on the role of talent management on organisational performance in companies listed in Nairobi security exchange in Kenya, reveals that talent management studies had no direct link talent management with the organisational performance. In the paper presented by Waheed (2012), he alluded to the view that many organisations still act in traditional ways when it comes to human resource management practices and organisational manpower issue. Moreover, the Y generation management challenges are too demanding in that to overcome them, it can only be addressed through talent management at the moment (an internal "talent pool" within the organisation), and he proposed four approaches to use that other studies also suggest.

In a review conducted by Barkhuizen et al. (2014) while investigating the relationship between talent management, work engagement and service quality orientation of support staff in higher education institutions, a sample of 60 support staff was done in the quantitative manner using exploratory factor analysis and Cronbach alpha coefficient. The findings of the study reveal that the mean value ranged between 1.7477 and 2.9372. This meant that TM practices seemed lacking and problematic in these institutions. Moreover, the respondents indicated low levels of experience towards TM practices. Therefore, the significant difference existed between their practices and what the ideal situation should be towards institutional performance.

Moreover, this enormous challenge was more felt due to Janus faces and situation experienced, whereby young talents are so scarce and unstable in station of work coupled with high demands from the employer, while the existing human 
resources are ageing and nearing the retirement moment, hence calling for investigation of more scholarships. For instance, in 2010 alone, 303,000 scholarships were awarded for the same effect.

In the USA and Canada, study findings seem to not be so different from what has been established elsewhere in the world. HANOVER research (2010) in its findings about best practices in HRM and TM by higher education institutions reveals that higher education respondents lagged behind in key areas of implementing HRM practices. However, there were hopes that if these institutions change their style of operation to the desired environment, efficient ways to cope up with the time and address the stressing factors of shrinking budgets and ageing workforce.

On the contrary, Nutakki et al. (2015) in their study done on relationship between TM and psychological contracts in HEIs in India, data was collected from a sample of 400 employees, the Cronbach alpha measured 0.092 after exploratory factor analysis and regression analysis, the results reveal there is a correlation between TM practices and psychological contracts. Meaning the way the two are handled by human resource officers strengthens or weakens the practice. However, the demographic issues were not considered to establish its influence in the whole process.

The qualitative study design findings got from 40 people through interviews and observations insinuated that there was no systematic process to management of talents. The onus was left to ownership of the institutions to influence the practices through advertisements and recommendations from the referees. This meant that the issues of career planning and succession planning skills were found to be at disarray due to the fact that skills development and retention are not done within the institution itself. On the positive side, it can be said that performance appraisal was done but still at a level of implementation. Through observation, it was deduced that these institutions cannot perform on the world stage market due to low levels of employees' standards.

In addition, in South Africa, the situation seemed to give similar results as per prior reviews done though varied in population and the place where the quantitative study was done. This was an experimental cross-sectional survey with an aim to establish how relevant is TM in South African local government institutions. The analysis was done using ANOVA and MANOVA on a sample population of 578 in which $56.2 \%$ were females, with $74.4 \%$ having working experience on the same job. The findings disclosed that TM practices were not given due attention as seen in previous studies. The study done using exploratory factor analysis provided $66.88 \%$ with $95 \%$ confidence of variance interval greater than $p$ value $(P<0.05)$ (Barkhuizen 2014).

Another study on the similar variable with the main objective of exploring the application of talent management practices in local government institutions confirmed that talent practices were not receiving sufficient attention in the public sector due to its poor application and the lack of commitment from the management. The same survey revealed that demographic factors determine a significant difference on their demographic characteristics. This was done through exploratory factor analysis with $66.88 \%$ and component matrix. The result of sampling adequacy was 
0.927. MANOVA had a lambda value for age equal to $0.911[F(32,2088.900)=1.667$, $p$ 0.05].

What is more, a qualitative study was done still in Kenya by Gakure et al. (2013) with an aim of finding out whether reward management influences talent management in Kenyan universities. The finding revealed that universities had attracted committed staff and managed to retain them. However, challenges were still in place due to inequality and unfairness of the same reward system used. This system seemed to be affected by the payment and recruitment of part-time staff. In the USA, the population studied still revealed that the best way to improve organisational performance was through talent management. This was generated from a sample composed of $61.4 \%$ males and $38.6 \%$ females. The study aimed at establishing the contribution of awareness and development of talent management within construction companies. The same study reveals that effective and skilled human capital can be enhanced through talent practices to increase productivity and quality services both on the side of the organisation and customer. This can be done through collaboration in terms of sharing knowledge and teamwork.

In addendum to the above, in 2014, a study was done by DA magazine and Cornerstone on Demand, with the purpose of establishing how the districts were managing the biggest challenge of human resources and how they could address the issues of the time. The survey question of multiple choice collected from 316 revealed that $25 \%$ of the principles, $26 \%$ administrators and $19 \%$ superintendents were still handling talent in a traditional manner. Whereas $49 \%$ and $15 \%$ were satisfied with the mode of operation even though they were unsure of the alternative for unified management practices, $28 \%$ of the district used talent management systems, and $80 \%$ were either concerned or highly concerned about the teacher quality and student outcomes.

Similarly, in a study done in India on embryonic need for talent management systems in technical institutions, in their qualitative study which aimed at exploring growth of an organisation are dealing with this new talent context, their findings deduce that talent availability and quality are now tangible imitation to strategic growth of an organisation. This is because there is a clear shift from its full establishment; however its barriers were also found perhaps to be human resource itself who work at risk fighting the challenges than embracing it in the UK.

A study conducted by Jacob et al. (2014) has the purpose of examining the factors that influence the poor retention rate of academic staff at selected universities in South Africa. A population sample of 80 academic staff with more 10 years working experience was surveyed. The results revealed that the factors motivating staff involved both intrinsic and extrinsic issues which made respondents to consider an academic profession as a meagre-paying profession, of which its resources influence with little opportunity for growth. However, strings were attached on the salary as a concern, even though the profession is considered as a superior reputation in society. More so, many academics believe that a heavy workload makes it difficult to meet promotion requirements and poor mentoring and capacity development, which would benefit from academic support, unambiguous promotion guidelines 
and clear, homogenous salary packages, hence killing the whole agenda of talent development practices. The same study revealed that the student/lecturer ratio was quite impressive at comparisons among 23 universities; however, when it is cascaded at the individual university level, the matter of fact is that the challenge is different, as lecturers are overloaded depending on the department or programme headcount. Therefore, this whole matter reflects the impact of academic staff recruitment and retention.

\subsection{A Leaf Borrowed from the Findings of the Business Sector}

However, in their study done on 17 leaders of state-owned enterprises in China revealed that members had knowledge about TM leadership practices even though there was a gap in practice and actualisation of its systems. This qualitative study done with interviews and grounded theory approach to interpret and analyse data further reveals that TM practices require to be demonstrated at all levels within an organisation for better quality performance and quality services delivery.

Other studies, for example, Kibui (2015), with the main objective of establishing the effect of talent management on employees' retention in Kenya's state corporations, the study finding generated through descriptive survey using exploratory factor analysis from 382 sample population with a value of 0.951 , divulge that organisational processes related to retaining high-performing employees, with competencies, are now a focal point, so as to help organisations become successful and understand where to focus resources such as incentives, coaching and training programmes. Moreover, Namusonge, Kibui and Gachuanga's study findings on the Role of Talent Management on Employees Retention in Kenya in 2014 on 299 employees seemed to be alarming, whereby it was discovered that $38 \%$ of talent staff left government jobs in favour of private enterprises. However, in their conclusion it was observed that most of those who had gone away were quality staff, meaning that the success of any organisation mostly depends on the talented human resources.

Farahas' study in 2014 proposed a model that could provide possible solutions to Saudi Arabia's tourism sector. The sector seemed to have had challenges rotating on talent management and organisational performance. Therefore, to optimise turnover quality performance, he suggested a model for talent practices.

Equally in another study done by Iqbal et al. (2013) with an aim of establishing the relationship between different talent management activities and traditional human resource management practices, data were collected from 130 HRM professionals in 25 companies and analysed using regression and mean, standard deviation and correlation results. Results revealed reward management that $\left(r=0.43^{* *}\right.$, mean $=3.48, \mathrm{SD}=0.82 ; P<0.05)$ talent management practices $\left(r=0.588^{* *}\right.$, mean $=3.51, \mathrm{SD}=0.73 ; p<0.05)$ and workforce planning $(r=0.611 * *$, mean $=3.67$, $\mathrm{SD}=0.71 ; p<0.05)$ have a positive relationship with organisational performance, 
whereas, employees' emotional stability mediates relationship between TM practices and OP (organisational performance) $\left(r=0.65^{* *}\right.$, mean $=3.51$, SD $=0.72$; $p<0.05$ ); employees' emotional stability mediates relationship between work.

In the same study, results reflected that talent management practices $(r=0.588 * *$, mean $=3.51, \mathrm{SD}=0.73 ; p<0.05)$ are positively related with the performance of organisation. Further still employees' emotional stability mediates relationship between $\mathrm{TM}$ practices and $\mathrm{OP}\left(r=0.65^{* *}\right.$, mean $\left.=3.51, \mathrm{SD}=0.72 ; p<0.05\right)$. This meant that there is a significant relation between skill full, competent staff and organisational performance. Therefore, the impact of grooming talents should not be underestimated by higher educational institution authorities due to its outcomes for the future betterment and sustainability of qualified staff.

\subsection{Summary of the Findings}

From the literature reviewed related to talent management practices, the study highlights the major best practices of the system, and some of the literature has been on talent and job satisfaction, organisational performance, retention, and turnover reward management but all trying to allude that talent practices have a lot of influence on the employee and organisational performance. The best practices are highlighted as enumerated in the studies reviewed sticking on Davies and Davies (2010); talent identification is the process and activities defining and discovering the required human resources needed for improved organisational performance. It involves recruitment of high calibre people, who will be enthusiastic and highly capable to deal with global challenges facing the institutions without affecting its values, identity, beliefs and mission.

Talent development can be concluded as a process of enabling learning and skills development in line with the organisations' development agendas so as to occupy the leadership vacuum. Institutions inject capital into staff professional development in line with the university mission and vision with the view of meeting quality services.

Talent culture: these are planned activities to enhance replacement of aged and retiring staff. Institutions prepare staff who are loyal and committed in the form of retention with the purpose of developing them to step up forces to enable the institution to achieve its agendas.

\subsection{Recommendations}

Basing on the challenges cited above, higher education institutions need to lay out strategies of addressing talent management through the following ways. 
Collaboration and networking with one another to boost capacity building. This can be done through the use of links between both developed and undeveloped universities, local and international, to sustain future quality demands.

Leadership also needs to come to grips with talent management strategy since it is the only way through which sustainability and stability of higher education institutions can survive in the world market.

\subsection{Conclusion}

In today's competitive environment, higher education institutions should constantly invest in human capital so as to remain relevant in the changing world market. It requires both the top management officials and HR professionals to cowork so as to attract, hire, develop and retain high potential young talents for leadership sustainability and improved organisational quality services. However, management should also put into consideration the fact that talent management is chaotic in nature, hard to maintain, fragile and scarce. This is because young blood with skills and abilities are unstable, easy to lose and too demanding. This has not only constituted a major obstacle in TM process for organisational stability but also has led to systems failure in terms of quality control and customer service delivery. Future-oriented higher education institution (HEI) leadership must review their policies through examination of the available workforce trends so as to keep on the stage of the world market economy. The influential unstable trends include changing demographics and global supply mechanisms, summed up with scarcity of younger talent and abundance of older workforce and growing migration of talented individuals which must be approached differently basing on the locality and status of the institution in order to achieve sustainable competitive success and transformation.

\section{References}

Afiouni, F. (2009). Leveraging human capital and value creation by combining HRM and KM initiatives'. International Journal of Learning Intellectual Capital, 6(3), 202-213.

Allen, S. (2004). Talent management systems: Best practices in technology solutions for recruitment, retention and workforce planning. Wiley, Feb 12, 2010, Business \& Economics.

Annakis, J., Dass, M., \& Isa, A. (2014). Exploring factors that influence talent management competency of academics in Malaysian GLC's and non- government universities. Journal of International Business and Economics, 2(4), 163-185.

Al-Atari, A. T., \& Rosnani Hasim, M. H. (2015). In M. H. Rosnani Hashim (Ed.), Critical issues and reform in Muslim higher education. IIUM Press (First Edit). Kuala Lumpur Malaysia: IIUM Press, IIUM.

Barkhuizen, N. (2014). How relevant is talent management in south african local government institutions? Mediterranean Journal of Social Sciences. MCSER Publishing, Rome-Italy 5 No 20, ISSN 2039-2117. 
Barkhuizen, N., Mogwere, P., \& Schutte, N. (2014). Talent management, work engagement and service quality orientation of support staff in a higher education institution. Mediterranean Journal of Social Sciences, 5(4), 69-77. https://doi.org/10.5901/mjss.2014.v5n4p69.

Barsade, S. G., \& Donald, E. G. (2007). Why does affect matter organisation? The Academy of Management Perspectives, 21(6), 36-59.

Becker, B. E., \& Huselid, M. A. (2006). Strategic human resource management: Where do we go from here? Journal of Management, 32, 898-925.

Bjorkman, I., Farndale, E., Morris, S. S., Pauuwe, J., Stiles, P., Trevor, J., \& Wright, P. M. (2012). Six principles of effective global talent management. Sloan Management Review, 53(2), 25-42.

Boudreau, J. W., \& Ramstad, P. M. (2005). Talent ship, talent segmentation, and sustainability: A new HR decision science paradigm for a new strategy definition. Human Resource Management, 42, 129-136.

Cappelli, P. (2008). Talent management for the twenty-first century. Harvard Business Review, $74-81,3$.

Cheese, P., Thomas, R. J., \& Craig, E. (2008). The talent powered organisation: Strategies for globalisation, talent management and high performance. London: Kapan.

Chuai, X., Iles, P., \& Preece, D. (2010). Talent management and HRM in multinational companies in Beijing: Definitions, differences and drivers. Journal of World Business, 45(2), 179-189.

CIPD. (2006). Talent management: Understanding the dimensions. London: CIPD.

Collings, D. G., Scullion, H., \& Dowling, P. J. (2009). Global staffing: A review and thematic research agenda. The International Journal of Human Resource Management, 20(6), 1253.

Davies, B., \& Davies, B. J. (2010). Talent management in academies. International Journal of Education Management, 24, 5. Emerald insight.

Fraynas, J. G., Millahi, K., \& Pigman, G. A. (2006). First mover advantages of in international business and firm-specific political resources. Strategic Management Journal, 27(4), 321-345.

Gakure, R. W., Kamau, A. W., \& Waititu, A. G. (2013). Reward systems as determinant of talent management in public universities in Kenya. IOSR Journal of Humanities and Social Science (IOSR-JHSS), 18, 2. (Nov-Dec 2013) 41-47 e-ISSN: 2279-0837, p-ISSN: 2279-0845. www. iosrjournals.org.

Garavan, T. N., Carbery, R., \& Rock, A. (2012). Mapping talent development: Definition, scope and architecture. European Journal of Training and Development, 36(1), 5-24.

Garrow, V., \& Hirsh, W. (2008). Talent management: Issues of focus and fit. Public Personnel Management, 37(4), 389-402.

Goffee, R., \& Jones, G. (2007). Leading clever people. Harvard Business Review, 85(3), 72.

Guthridge, M., Komm, A. B., \& Lawson, E. (2008). Making talent management a strategic priority. The McKinsey Quarterly, 1, 49-59.

Hanover Rsearch. (2010). Market evaluation surveying data analysis benchmarking innovative practices literature review 1101 Connecticut Ave. NW, Suite 300, Washington, DC 20036 P 202.756.2971 F 866.808.6585. www.hanoverresearch.com

Hernaus, T. (2008). Generic process transformation model: Transition to process-based organization. Business, 385(08), 1-16.

Ingham, J. (2006). Closing the talent management gap. Strategic HR Review, 5(3), $20-23$.

Iqbal, S., Qureshi, T. M., Khan, A. M., \& Hijaz, S. Y. T. (2013). Talent management is not an old wine in a new bottle. African Journal of Business Management, 7(35), 3609-3619. https://doi. org/10.5897/AJBM11.855ISSN19938233. Academic Journals http://www.academicjournals. org/AJBM.

Isahak, A. (2007). "The philosophy of higher education of the 21st century.” Bulletin of National Higher Education Research Institute (IPPTN), 10(1), 15-16.

Iyria, R. K. (2013). Role of talent management on organization performance in companies listed in Nairobi security exchange in Kenya: Literature review. International Journal of Humanities and Social Science, 3, 21. [Special Issue].

Jacob, M., Selesho, J. M., \& Naile, I. (2014). Academic staff retention as a human resource factor: University perspective. International Business \& Economics Research Journal, 13, 2. 
Kibui, A. W. (2015). Effect of talent management on employees' retention in Kenya's state corporations, a thesis submitted in partial fulfilment for the degree of doctor of philosophy in human resource management in the Jomo Kenyatta University of Agriculture and technology.

Lewis, R. E., \& Heckman, R. J. (2006). Talent management: A critical review. Human Resource Management Review, 16(2), 139-154.

Nair, J. P. (2012). Is talent management accentuated by competency mapping? with special reference to educational sector. International Journal of Social Science \& Interdisciplinary Research, 1, 11. ISSN 22773630.

Nutakki, R., Reddy, M. S., \& Balan, S. (2015). A study of the relationship between talent management and psychological contract international conference on science and technology university of Delhi(du) conference centre new Delhi(India) Lakshmi.

Ready, D. A., \& Conger, J. A. (2007). Make your company a talent factory. Harvard Business Review, 85, 68-77.

Ringo, T., Schweyer, A., De Marco, M., Jones, R., \& Lesser, E. (2008). Integrated talent management part 3 training talent management into a competitive advantage: An industry review (no.3) (p24). Human capital institute, IBM Institute for Business value. Retrieved from http:// be.hci.org/hci/IBM_2008

Rudhumbu, N. (2014). Implementation of talent management strategies in higher education: Evidence from Botswana. International Journal of Higher Education, 1(1), 86-99.

Sahney, S., Banwet, D. K., \& Karunes, S. (2004). Research and concepts; conceptualising total quality management in higher education institutions. The Total Quality Magazine, 16, 2. Emerald group of publishing company Limited.

Schuler, R. S., Jackson, S. E., \& Tarique, I. (2011). Global talent management and global talent challenges: Strategic opportunities for IHRM. Journal of World Business, 46(4), 506.

Scott, P. (2000). Higher education re-formed. London: Falmer press 11 New Fetter Lane.

Scullion, H., Collings, D. G., \& Caligiuri, P. (2010). Global talent management, editorial. Journal of World Business, 45, 105-108.

Simonton, D. K. (2011). Exceptional talent and genius. In T. Chamorro-Premuzic, S. von Stumm, \& A. Furnham (Eds.), The Wiley-Blackwell handbook of individual differences (pp. 635-655). Malden: Wiley-Blackwell.

Stahl, G. K., Björkman, I., Farndale, E., Morris, S. S., Paauwe, J., Stiles, P., Trevor, J., \& Wright, P. M. (2012). Six principles of effective global talent management. Sloan Management Review, 53(2), 25-32.

Sumardi, W. A., \& Othman, R. (2009). The three faces of talent management in Malaysia. International Journal of Business Research, 10(1), 181-185.

Tarique, I., \& Schuler, R. S. (2010). Global talent management; Literature review, integrative framework, and suggestions for further research. Journal of World Business, 45(2), 122-133.

Tiwari, U., \& Shrivastav, D. (2013). Strategies and practices of talent management and their impact on employee retention and effectiveness. 2 The International Journal of Management, 2, 4. The University of British Columbia, Vancouver, BC, Canada and McMaster University, Hamilton, ON, Canada.

Vaiman, V., Scullion, H., \& Collings, D. (2012). Talent management decision making. Management Decision, 50(5), 925-941. https://doi.org/10.1108/00251741211227663.

Waheed, S., Zaim, A., \& Zaim, H. (2012). Talent Management in four stages the USV. Annals of Economics and Public Administration, 12(1(15)), 130-137. 